\title{
Exploring GGBS Utilization in Construction of Residential Projects \& Its Contribution toward Environment
}

\author{
Mr. Shibashish P. Mukherjee ${ }^{1}$, Dr Gaurang Vesmawala ${ }^{2}$, Mr. Sanjay C Shah ${ }^{3}$ \\ ${ }^{I}$ P.G Student in Applied Mechanic Sardar Vallabhai Institute of Technology, Surat, Gujarat, India \\ ${ }^{2}$ Assistant Professor in Applied Mechanic Sardar Vallabhai Institute of Technology, Surat, Gujarat, India \\ ${ }^{3}$ Chief Managing Director of Cube Construction Engineering Ltd Vadodara, Gujarat, India
}

\begin{abstract}
The utilization of supplementary cementation materials is well accepted, since it leads to several possible improvements in the concrete composites, as well as the overall economy. The present paper is an effort to quantify the strength of ground granulated blast furnace slag (GGBS) at various replacement levels and evaluate its efficiencies in concrete. Cement with GGBS replacement has emerged as a major alternative to conventional concrete and has rapidly drawn the concrete industry attention due to its cement savings, energy savings, cost savings, environmental and socio-economic benefits. Today's construction industry, use of concrete is going on increasing rapidly. Cement is major constituent material of the concrete which produced by natural raw material like lime and silica. Once situation may occurs there will be no lime on earth for production of cement. This situation leads to think all people working in construction industry to do research work on cement replacing material and use of it. Industrial wastes like Ground Granulated Blast Furnace Slag $(G G B S)$ show chemical properties similar to cement. Use of GGBS as cement replacement will simultaneously reduces cost of concrete and help to reduce rate of cement consumption. This study report consist of literature review on utilization of GGBS as partial replacement of cement in concrete, which will give assurance to encourage people working in the construction industry for the beneficial use of it. The Housing for All projects which is a dream projects of Hon Prime minister of India, Shri Narendra Modiji can contribute substantial in saving in emission of Green House Gas. It also discusses the Government Policy in maximizing utilization of supplementary cementation materials
\end{abstract}

Keywords: Compressive Strength, of Concrete, CCEL, Ground Granulated Blast Furnace Slag, Ordinary Portland cement, Sustainability,

\section{Introduction}

The production of cement is an energy intensive process, resulting in emission of green house gases which adversely impact on the environment. At the same the cost of production of cement is increasing at alarming rate and natural resources giving the raw material for its manufacturing are depleting. The use of waste material having cementitious properties as a replacement of cement in cement concrete has become the thrust area for construction material experts and researchers. The main focus now a day is on search of waste material or bye product from manufacturing processes, which can be used as partial replacement of cement in concrete, without compromising on its desired strength. The ground granulated blast furnace slag (GGBS) is a waste product from the iron manufacturing industry, which may be used as partial replacement of cement in concrete due to its inherent cementing properties. In the country like India, where the development of the infrastructures projects such as large irrigation, road and building projects are either being constructed or in completion of their planning and design stage, such uses of waste material in cement concrete will not only reduce the emission of green house gases but also will be the sustainable way of management of waste. The Fly ash (FA), GGBS, Rice Husk Ash (RHA), and Silica Fume (SF) are some of the pozzolanic materials which can be used in concrete as partial replacement of cement. A number of studies are going on in India as well as abroad to study the impact of use of these pozzolanic materials as cement replacements and the results are encouraging. These materials include fly ash, silica fume and ground-granulated blast furnace slag used separately or in combination. The strength, durability and other characteristic of concrete depends on the properties of its ingredients, proportion of mix, method of compaction and other controls during placing and curing. For concretes, a combination of mineral and chemical admixtures is always essential to ensure achievement of the required strength.

\subsection{Background}

GGBS is not a new product. It has already proven itself reliably in its use all over the world since the mid 1800s. Thirty-eight years after the patent for Portland cement was first lodged by John Aspdin in 1824, Emil Langin discovered GGBS cement. By 1865, commercial production of lime activated GGBS had commenced in Germany and by 1880 GGBS was being used with Portland cement as the activator. In 1889 it was used for construction of the Paris Metro. The United States commenced production of slag cements in 1896. 
Since then Europe, with its many blast furnaces and steel industries has used GGBS extensively in all manner of structures. By 1914, GGBS was being manufactured in Scotland. BS 146 was published in 1923 followed by BS 6699 in 1986 for GGBS. In Britain, over 2 million tones of GGBS is used every year. GGBS is also widely used by the cement and concrete industries in continental Europe, with some 17.7 million tones now being used annually. GGBS is specified for its many technical advantages and as a means of reducing the environmental impact of the production of Portland cement.

1862: Hydraulic potential of GGBS discovered in Germany

Early 1900's -Portland Blast Furnace Cements had an established place in the concrete market

2004: More than 5,000,000 tones of GGBS produced in Germany

2006: Approximately 2,000,000 tones of GGBS produced in UK

2008: Over 400,000 tones available in Ireland.

\subsection{Definition of Ground-Granulated Blast-Furnace Slag}

Blast furnace slag is a by-product of iron manufacturing industry. Iron ore, coke and limestone are fed into the furnace, and the resulting molten slag floats above the molten iron at a temperature of about $1500 \mathrm{o} C$ to $1600 \mathrm{oC}$. The molten slag has a composition of $30 \%$ to $40 \%$ silicon dioxide ( $\mathrm{SiO} 2$ ) and approximately $40 \% \mathrm{CaO}$, which is close to the chemical composition of Portland cement. After the molten iron is tapped off, the remaining molten slag, which mainly consists of siliceous and aluminous residues, is then rapidly waterquenched, resulting in the formation of a glassy granulate. This glass granulate is dried and ground to the required size which is known as ground granulated blast furnace slag (GGBS).

\subsection{Production and composition}

The chemical composition of a slag varies considerably depending on the composition of the raw materials in the iron production process. Silicate and aluminate impurities from the ore and coke are combined in the blast furnace with a flux which lowers the viscosity of the slag. In the case of pig iron production the flux consists mostly of a mixture of limestone and forsterite or in some cases dolomite. In the blast furnace the slag floats on top of the iron and is decanted for separation. Slow cooling of slag melts results in an un-reactive crystalline material consisting of an assemblage of $\mathrm{Ca}-\mathrm{Al}-\mathrm{Mg}$ silicates. To obtain a good slag reactivity or hydraulicity, the slag melt needs to be rapidly cooled or quenched below $800{ }^{\circ} \mathrm{C}$ in order to prevent the crystallization of merwinite and melilite. To cool and fragment the slag a granulation process can be applied in which molten slag is subjected to jet streams of water or air under pressure. Alternatively, in the pelletization process the liquid slag is partially cooled with water and subsequently projected into the air by a rotating drum. In order to obtain a suitable reactivity, the obtained fragments are ground to reach the same fineness as Portland cement.

The main components of blast furnace slag are $\mathrm{CaO}(30-50 \%), \mathrm{SiO}_{2}(28-38 \%), \mathrm{Al}_{2} \mathrm{O}_{3}(8-24 \%)$, and $\mathrm{MgO}(1-18 \%)$. In general increasing the $\mathrm{CaO}$ content of the slag results in raised slag basicity and an increase in compressive strength. The $\mathrm{MgO}$ and $\mathrm{Al}_{2} \mathrm{O}_{3}$ content show the same trend up to respectively $10-12 \%$ and $14 \%$, beyond which no further improvement can be obtained. Several compositional ratios or so-called hydraulic indices have been used to correlate slag composition with hydraulic activity; the latter being mostly expressed as the binder compressive strength.

The glass content of slags suitable for blending with Portland cement typically varies between 90-100\% and depends on the cooling method and the temperature at which cooling is initiated. The glass structure of the quenched glass largely depends on the proportions of network-forming elements such as $\mathrm{Si}$ and $\mathrm{Al}$ over network-modifiers such as $\mathrm{Ca}, \mathrm{Mg}$ and to a lesser extent Al. Increased amounts of network-modifiers lead to higher degrees of network de-polymerization and reactivity.

Common crystalline constituents of blast-furnace slags are merwinite and melilite. Other minor components which can form during progressive crystallization are belite, monticellite, rankinite, wollastonite and forsterite. Minor amounts of reduced sulphur are commonly encountered as oldhamite.

The production of GGBS requires little additional energy compared with the energy required for the production of Portland cement. 


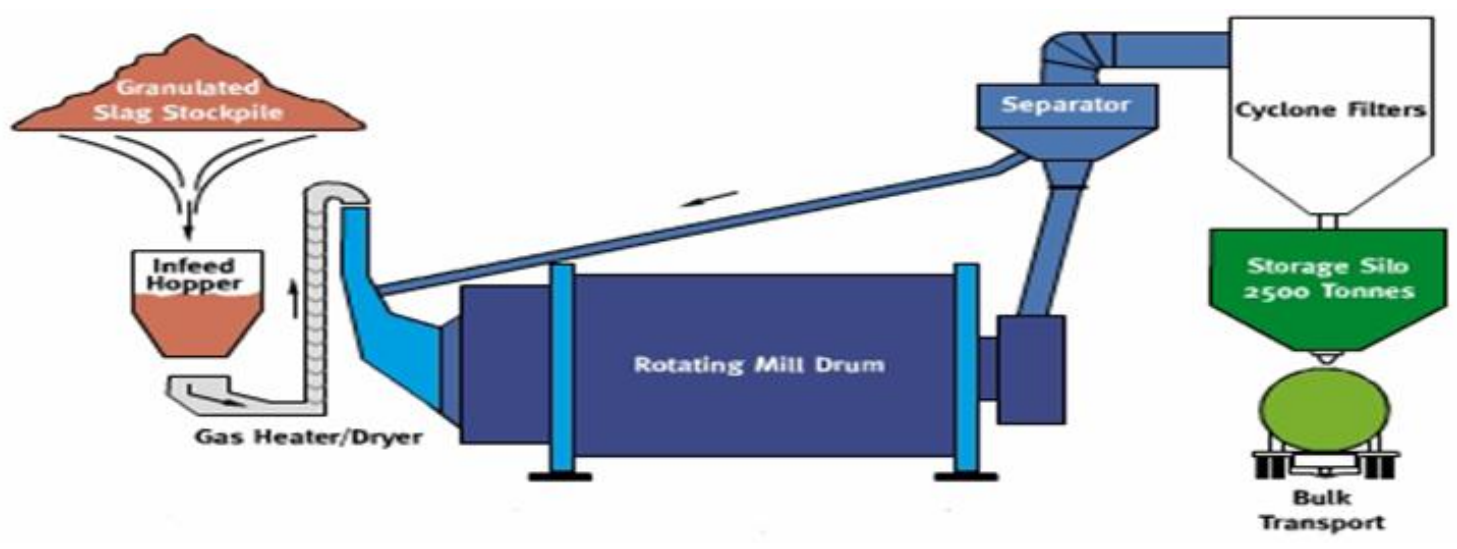

\section{Literature Review}

Shariq et al. (2008) studied the effect of curing procedure on the compressive strength development of cement mortar and concrete incorporating ground granulated blast furnace slag. The compressive strength development of cement mortar incorporating 20,40 and 60 percent replacement of GGBFS for different types of sand and strength development of concrete with 20, 40 and 60 percent replacement of GGBFS on two grades of concrete are investigated. Tests results show that the incorporating $20 \%$ and $40 \%$ GGBFS is highly significant to increase the compressive strength of mortar after 28 days and 150 days, respectively.

Peter et al. (2010) studied the BS 15167-1 which requires that the minimum specific surface area of GGBS shall be $2750 \mathrm{~cm} 2 / \mathrm{g}$ (BS 15167-1:2006). In China, GGBS is classified into three grades; namely S75, S95 and S105. The GB/T18046 requires a minimum surface area of $3000 \mathrm{~cm} 2 / \mathrm{g}$ for grade S75 GGBS, 4000 $\mathrm{cm} 2 / \mathrm{g}$ for grade S95 and $5000 \mathrm{~cm} 2 / \mathrm{g}$ for grade S105, which are higher than the BS EN's requirements (GB/T18046-2008). It was reported that slag with a specific surface area between $4000 \mathrm{~cm} 2 / \mathrm{g}$ and $6000 \mathrm{~cm} 2 / \mathrm{g}$ would significantly improve the performance of GGBS concretes.

Elsayed (2011) investigated experimentally in his study the effects of mineral admixtures on water permeability and compressive strength of concretes containing silica fume (SF) and fly ash (FA). The results were compared to the control concrete, ordinary Portland cement concrete without admixtures. The optimum cement replacement by FA and SF in this experiment was $10 \%$. The strength and permeability of concrete containing silica fume, fly ash and high slag cement could be beneficial in the utilization of these waste materials in concrete work, especially in terms of durability.

Martin et al. (2012) studied the influence of $\mathrm{pH}$ and acid type in the concrete. The conclusions were that concrete tested cannot adequately address the durability threat to all parts of wastewater infrastructure over a significant life span due to the extraordinarily harsh nature of this form of attack.

Wang Ling et al. (2004) analyzed the performance of GGBS and the effect of GGBS on fresh concrete and hardened concrete. GGBS concrete is characterized by high strength, lower heat of hydration and resistance to chemical corrosion.

Vinayak Awasare \& Prof. M.V. Nagendra. (2013) analyzed the properties of cement with GGBS and prepared Mix Design of concrete as per IS 102621983 on normal concrete and on GGBS concrete with proportion $20 \%, 30 \%, 40 \%, 50 \%$ cement replacement. The comparative report prepared shows that the M20 plain cement concrete prepared by OPC \& Natural sand with $20 \%, 30 \%, 40 \%, 50 \%$ cement replacement has more strength than Concrete of only OPC at 28 days. The flexural strength is also more than normal plain concrete with respect to concrete with different GGBS Content.

K. Suvarna Latha, M.V Seshagiri Rao \& Srinivasa Reddy. V (2012) studied the behavior of concretes with GGBS and HVFA as direct replacement for 53 grade OPC, on a one to one basis by weight in order to quantify the strength efficiency of GGBS \& HVFA in concrete at $28,90 \& 180$ days. Replacement levels for GGBS \& HVFA vary from $10 \%$ to $70 \%$ in an increment of $10 \%$. Typically $40 \%$ being the optimum percentage replacement of HVFA in ordinary grade concrete of 50\% in Standard \& high grade concrete. In case of GGBS concrete $40 \%$ being the optimum percentage in ordinary grade concrete \& in Standard concrete and $50 \%$ in high grade concrete.

S. Arivalagan (2014) this research evaluates the strength and strength efficiency factors of hardened concrete, by partially replacing cement by various percentages of ground granulated blast furnace slag for M35 grade of concrete at different ages. From this study, it can be concluded that, since the grain size of GGBS is less than that of ordinary Portland cement, its strength at early ages is low, but it continues to gain strength over a long period. The optimum GGBFS replacement as cementation material is characterized by high compressive strength, low heat of hydration, resistance to chemical attack, better workability, good durability and costeffectiveness. 
Kamran Muzaffar Khan (2004) In this research, GGBS (Ground Granulated Blast furnace Slag) was collected from Steel Mills Karachi (Pakistan) and pulverized to a very fine degree from a pulverizer. Physicall Chemical properties, such as, compressive strength, fineness, setting times, soundness and chemical composition of GGBS (Ground Granulated Blast furnace Slag) were investigated and comparison has been made with the relevant properties of cement Effect of replacement was seen on workability, compressive strength, tensile strength, modulus of rupture, equivalent cube strength by casting mixes of different ratios; $1: 2: 4,1: 1.5: 3,1: 1.25: 2.50,1: 1: 2$. WIC ratio for first two mixes was kept as 0.65 and for rest two mixes as 0.45.After cost comparison of GGBS and Ordinary Portland Cement it is concluded that p rice of G GBS is $25 \%$ to $50 \%$ less than that of Ordinary Portland Cement. This aspect of GGBS makes it economical.

Peter W.C. Leung \& H.D. Wong (2010) The PWCL has carried out a laboratory investigation on the strength development of GGBS concrete. A total of 30 concrete mix and seven curing environments were included in the study. Based on the results up to a test age of 364 days, the following conclusions can be drawn:

a) The PWCL's findings indicate that bleeding of concrete is not affected significantly by the inclusion of GGBS. When used in conjunction of silica fume, there appears to be a noticeable improvement in respect of the degree of bleeding.

b) As the temperature control measures were not imposed for the mixes used, there was no significant reduction in the peak temperature of GGBS concrete unless the replacement percentage is at least $80 \%$. Temperature control may need to be imposed to limit the peak temperature of the GGBS concrete.

c) The inclusion of GGBS appears to have a slight retarding effect on the early strengths of concrete. The 7day strengths of GGBS concrete were between $56 \%$ and $71 \%$ of the 28 -day strengths, as compared to about $80 \%$ for Portland cement concrete.

d) The strength development of GGBS concrete was affected by the curing temperature. Low curing temperature would result in low early strength of GGBS concrete. For high temperature curing at $75 \mathrm{oC}$, the 28-day strengths all fell short of their design strength and there may be a need to limit the peak temperature of concrete in mass pours in practice.

e) The GGBS concrete would require a longer curing period than that of Portland cement concrete. Insufficient curing (less than 3 days) could severely hamper the strength development.

f) The inclusion of GGBS would improve the concrete's ability to resist chloride penetration but the GGBS replacement percentage will need to be at least $70 \%$ for this purpose.

g) The inclusion of silica fume would significantly improve the concrete durability.

\section{Applications}

GGBS is used to make durable concrete structures in combination with ordinary portland cement and/or other pozzolanic materials. GGBS has been widely used in Europe, and increasingly in the United States and in Asia (particularly in Japan and Singapore) for its superiority in concrete durability, extending the lifespan of buildings from fifty years to a hundred years.

Two major uses of GGBS are in the production of quality-improved slag cement, namely Portland Blastfurnace cement (PBFC) and high-slag blast-furnace cement (HSBFC), with GGBS content ranging typically from 30 to $70 \%$; and in the production of ready-mixed or site-batched durable concrete.

Concrete made with GGBS cement sets more slowly than concrete made with ordinary Portland cement, depending on the amount of GGBS in the cementitious material, but also continues to gain strength over a longer period in production conditions. This results in lower heat of hydration and lower temperature rises, and makes avoiding cold joints easier, but may also affect construction schedules where quick setting is required.

Use of GGBS significantly reduces the risk of damages caused by alkali-silica reaction (ASR), provides higher resistance to chloride ingress - reducing the risk of reinforcement corrosion — and provides higher resistance to attacks by sulfate and other chemicals.

\subsection{Method of using GGBS in cement}

GGBS cement is added to concrete in the concrete manufacturer's batching plant, along with Portland cement, aggregates and water. The normal ratios of aggregates and water to cementitious material in the mix remain unchanged. GGBS is used as a direct replacement for Portland cement, on a one-to-one basis by weight. Replacement levels for GGBS vary from $30 \%$ to up to $85 \%$. Typically 40 to $50 \%$ is used in most instances.

The use of GGBS cement in concrete in Ireland is covered in the new Irish concrete standard IS EN 206-1:2002. This standard establishes two categories of additions to concrete along with ordinary Portland cement: nearly inert additions (Type I) and pozzolanic or latent hydraulic additions (Type II). GGBS cement falls in to the latter category. As GGBS cement is slightly less expensive than Portland cement, concrete made with GGBS cement will be similarly priced to that made with ordinary Portland cement. 


\subsection{Durability}

\section{Architectural And Engineering Benefits}

GGBS cement is routinely specified in concrete to provide protection against both sulphate attack and chloride attack. GGBS has now effectively replaced sulfate-resisting Portland cement (SRPC) on the market for sulfate resistance because of its superior performance and greatly reduced cost compared to SRPC. Most projects in Dublin's Docklands, including Spencer Dock, are using GGBS in subsurface concrete for sulfate resistance.

To protect against chloride attack, GGBS is used at a replacement level of 50\% in concrete. Instances of chloride attack occur in reinforced concrete in marine environments and in road bridges where the concrete is exposed to splashing from road de-icing salts. In most NRA projects in Ireland GGBS is now specified in structural concrete for bridge piers and abutments for protection against chloride attack. The use of GGBS in such instances will increase the life of the structure by up to $50 \%$ had only Portland cement been used, and precludes the need for more expensive stainless steel reinforcing.

GGBS is also routinely used to limit the temperature rise in large concrete pours. The more gradual hydration of GGBS cement generates both lower peak and less total overall heat than Portland cement. This reduces thermal gradients in the concrete, which prevents the occurrence of microcracking which can weaken the concrete and reduce its durability, and was used for this purpose in the construction of the Jack Lynch Tunnel in Cork.

\subsection{Appearance}

In contrast to the stony grey of concrete made with Portland cement, the near-white color of GGBS cement permits architects to achieve a lighter colour for exposed fair-faced concrete finishes, at no extra cost. To achieve a lighter colour finish, GGBS is usually specified at between 50\% to $70 \%$ replacement levels, although levels as high as $85 \%$ can be used. GGBS cement also produces a smoother, more defect free surface, due to the fineness of the GGBS particles. Dirt does not adhere to GGBS concrete as easily as concrete made with Portland cement, reducing maintenance costs. GGBS cement prevents the occurrence of efflorescence, the staining of concrete surfaces by calcium carbonate deposits. Due to its much lower lime content and lower permeability, GGBS is effective in preventing efflorescence when used at replacement levels of $50 \%$ to $60 \%$.

\subsection{Strength}

Concrete containing GGBS cement has a higher ultimate strength than concrete made with Portland cement. It has a higher proportion of the strength-enhancing calcium silicate hydrates (CSH) than concrete made with Portland cement only, and a reduced content of free lime, which does not contribute to concrete strength. Concrete made with GGBS continues to gain strength over time, and has been shown to double its 28 -day strength over periods of 10 to 12 years.

\subsection{Sustainability}

Since GGBS is a by-product of steel manufacturing process, its use in concrete is recognized by LEED etc. as improving the sustainability of the project and will therefore add points towards LEED certification. In this respect, GGBS can also be used for superstructure in addition to the cases where the concrete is in contact with chlorides and sulfates. This is provided that the slower setting time for casting of the superstructure is justified.

From structural point of view, GGBS replacement enhances lower heat of hydration, higher durability and higher resistance to sulphate and chloride attack when compared with normal ordinary concrete. On the other hand, it also contributes to environmental protection because it minimizes the use of cement during the production of concrete.

However, it is identified that there are still some hindrances that prevent the prevalence of its usage in local market. Technically speaking, GGBS concrete suffers from lower rate of strength development which is highly sensitive to curing conditions. In this connection, certain site measures have to be introduced to the construction industry to ensure better quality of curing process in order to secure high quality of GGBS concrete. On the other hand, designers have to be cautious of the potential bleeding problem of GGBS concrete.

Another major hurdle of extensive use of GGBS concrete lies in the little source of supply of GGBS. As Hong Kong is not a major producer of steel, GGBS as a by-product of steel has to be imported overseas and this introduces higher material cost due to transportation and the supply of GGBS is unstable and unsteady.

\section{Strength Development}

Concrete made with GGBS attains the same 28-day strength as concrete made with ordinary Portland cement (CEM I or CEM II/A), for replacement levels of GGBS up to 50\%. Concrete made with GGBS continues to gain strength over a very long period, and the ultimate strength of concrete made with GGBS is 
consistently higher than concrete made with CEM I or CEM II/A only. It is not unusual for a GGBS concrete to increase its 28 -day strength by a further $20 \%$ at 90 days. In laboratory investigations, GGBS concrete was shown to double its 28-day strength after 10 to 12 years, (Smolczyk, 1986).

Typical strengths of $35 \mathrm{~N}$ concrete $\left(\mathrm{N} / \mathrm{mm}^{2}\right)$ made with various percentages of GGBS are shown in the table below:

\begin{tabular}{|l|c|l|l|}
\hline GGBS \% & 7 day & 28 day & 56 day \\
\hline 0 & 32 & 42 & 43 \\
\hline 20 & 30 & 43 & 45 \\
\hline 35 & 27 & 43 & 47 \\
\hline 50 & 23 & 40 & 44 \\
\hline
\end{tabular}

These data are based on $300 \mathrm{~kg}$ CEM I mixes, with no admixtures added. CEM II cements in Ireland have the same performance as CEM I cements.

The higher ultimate strength of concretes made with GGBS is due to the fact that there is a greater proportion of the CSH (calcium silicate hydrate) gel and much less lime (calcium hydroxide) in the concrete, when GGBS is used. The CSH gel is the binder that holds together the aggregates and gives concrete its strength, whereas the lime contributes little to concrete strength.

\section{Field Study 2008}

In-situ concrete strength data was obtained on a project under construction in 2008 in Ireland. The following strength data was measured:

- Strength of standard site-cast cubes, which were cured in a lab at $20^{\circ} \mathrm{C}$

- Strength of the concrete in the in-situ element, using Temperature Matched Curing ${ }^{1}$

1. Temperature Matched Curing is curing concrete cubes in a water tank whose temperature matches the in-situ temperature in the concrete, using an electrical signal from a thermocouple placed in the concrete.The results show that both the in-situ strength and the standard cube strengths at 3 days are far greater than the minimum value of $10 \mathrm{~N} / \mathrm{mm}^{2}$ required for soffit formwork striking, as shown opposite

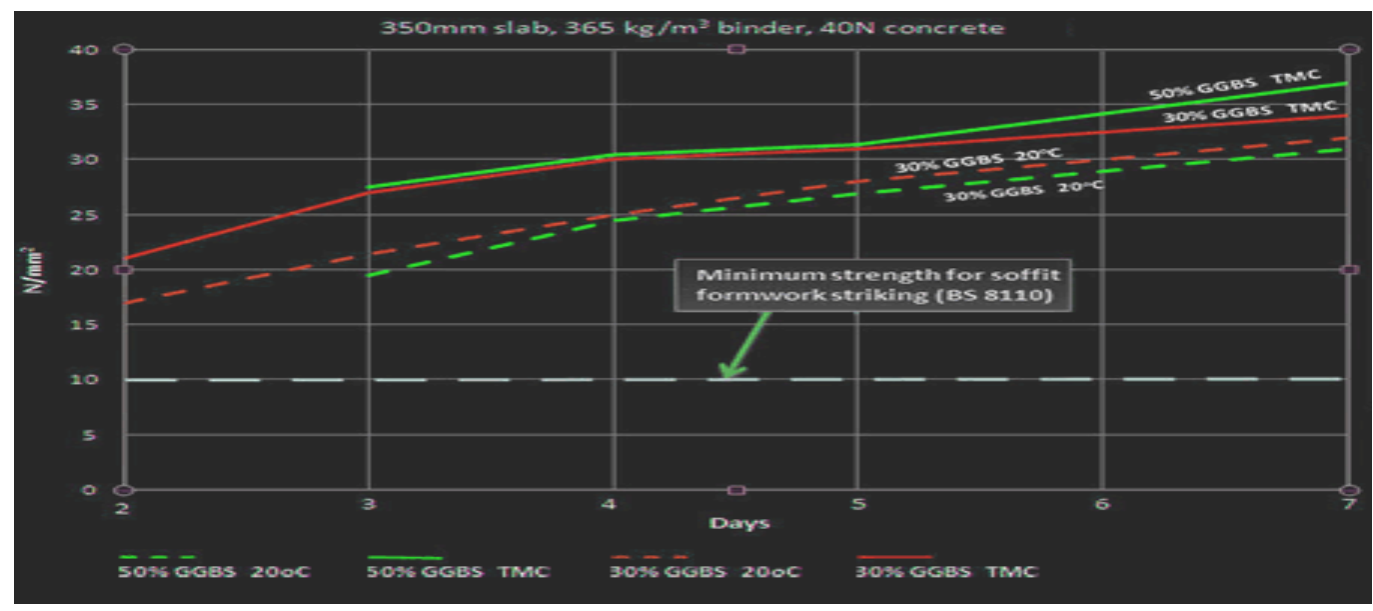

TMC and $20^{\circ} \mathrm{C}$ Strengths of Concretes with $30 \%$ and $50 \%$ GGBS

\subsection{Formwork Striking Times}

The time requirement for striking formwork, as per BS 8110 CEM 1 (Structural Use of Concrete), is 4 days for soffit formwork to slabs and $\mathbf{1 2}$ hours for vertical formwork (temperature to be $16^{\circ} \mathrm{C}$ ). However, shorter periods can be used, in particular for slabs or beams, if the concrete strength is at least $10 \mathrm{~N} / \mathbf{m m}^{2}$ (insitu), (or twice the stress to which the slab is subjected-which will normally be less that the $10 \mathrm{~N} / \mathrm{mm}^{2}$ value). In concrete slabs, the value of $10 \mathrm{~N} / \mathrm{mm}^{2}$ is normally the greater of these, unless the slab is very thin (less than $250 \mathrm{~mm}$ ) and also has a large span (greater than 7.5 metres). CIRIA report 136 (Formwork Striking Times) states that concrete is to have a strength of $\mathbf{2} \mathbf{N} / \mathbf{m m}^{2}$ or greater to prevent mechanical damage to vertical concrete elements when striking.

If the guidelines of BS 8110 are followed, experience in Ireland with concretes containing up 50\% GGBS (replacement for ordinary Portland cement) has shown that these requirements are met. There is also some 50 years plus experience in the UK with concretes where 50\% GGBS is regularly used, with no adverse 
affects to construction programmes. In 'Formwork Striking Times for GGBS Concrete', published by the Institution of Civil Engineers, the author states that:

"Where only up to $50 \%$ GGBS is used, the reduction in early age strength development has not presented problems significant enough to prompt much field investigation."

Concrete strength is normally measured on cubes cured at $20^{\circ} \mathrm{C}$. However in-situ concrete strength will differ from the cube strengths, due to the fact that in-situ concrete cures at temperatures in excess of $20^{\circ} \mathrm{C}$, and the section size is much larger than the standard cube dimension of $150 \mathrm{~mm}$. In the winter one needs to take account of the fact that insitu concrete curing temperature may be below $20^{\circ} \mathrm{C}$.

The in-situ strength of concrete in a slab depends on: Slab thickness

- $\quad$ Binder (cement/GGBS) content

- Formwork type

- Ambient temperature

- $\quad$ Time of formwork striking

Temperature Matched Curing (TMC) can be used to measure early age strength and assess striking times in critical elements. This method can give very accurate strength data, as it accurately monitors the internal temperature of the concrete and the corresponding in-situ strength.

It is normal practice in the UK, Belgium, France, Holland and other EU countries to use 50\% GGBS in a standard concrete mix. The experience in these countries has shown that at this replacement level of GGBS there is no need to extend formwork striking times.

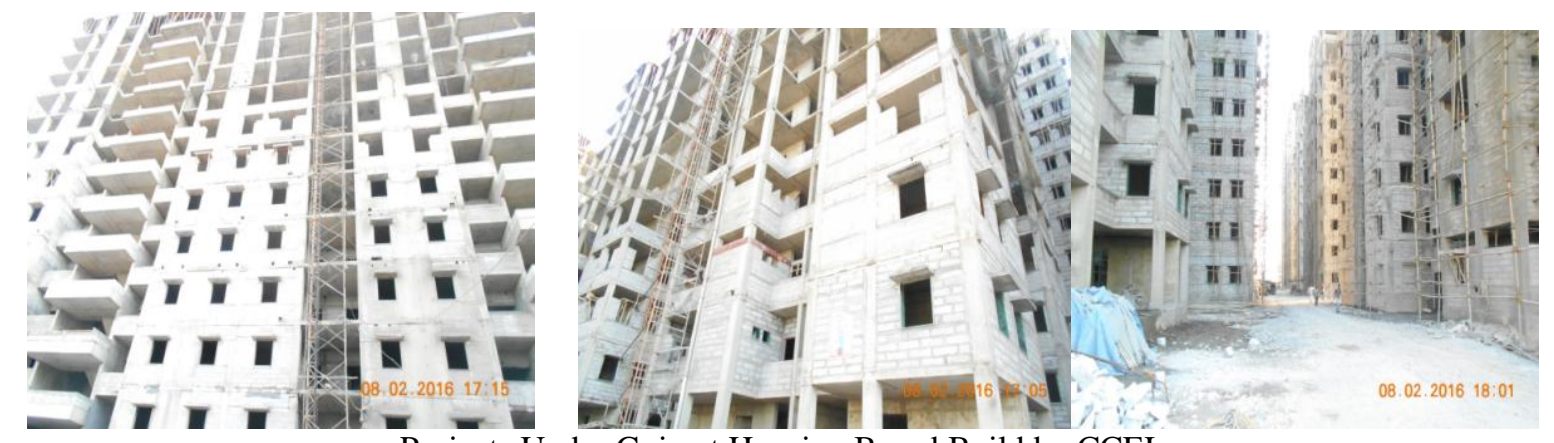

Projects Under Gujarat Housing Board Build by CCEL

VII. Temperature Effects

The rate of early age strength gain of GGBS concrete is greatly improved by higher curing temperatures, and is significantly more sensitive to elevated temperatures than that of concrete made with Portland cement only. In practical applications of GGBS, the raised temperature from the heat of hydration in the concrete element causes an increase in the rate of early age strength gain.

A temperature increase from 20 to $40^{\circ} \mathrm{C}$, commonly reached or exceeded in the curing of in-situ and precast concrete, is sufficient to increase the early strength GGBS concrete by a factor of two to four, (LERM, 2001). However, the same increase in temperature only increases the early strength of Portland cement concrete by a factor of 1.5 (Klieger, 1958).

The sensitivity of GGBS concrete to the temperature effect on strength development is often utilised by precast concrete manufacturers, where heated beds are used to accelerate early strength gain. For precast concrete elements, GGBS replacement levels are generally in the order of 25 to $40 \%$ although a higher $\%$ can be used where required, particularly for technical reasons.

As Per Soutsos, 2005 it shows that the early age strength gain of concrete made with GGBS is greater than that made with Portland cement. This is a direct result of the activation of the GGBS caused by the elevated temperatures present in in-situ concrete,

The effects of elevated temperatures on early age strengths (under adiabatic curing conditions) are illustrated in the graph below. Effectively, this graph illustrates that as the in-situ curing temperature increases, any delay in strength development that may arise as a result of increasing the \% of GGBS may be negated by the increase in temperature. 


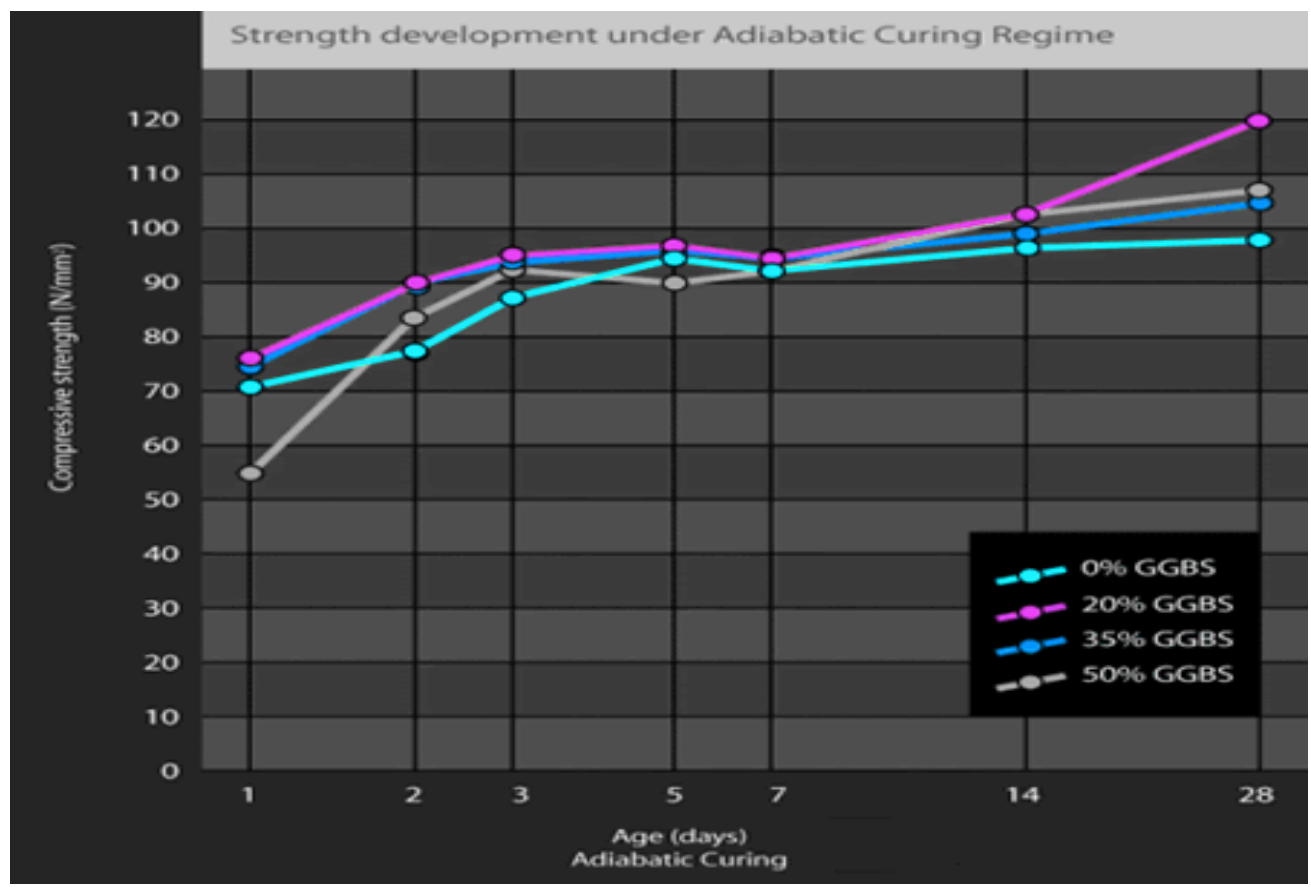

VIII. Curing

Good curing practice is essential for all concrete. Properly cured GGBS concrete is more durable and ultimately stronger than concrete made with Portland cement only. Water in GGBS concrete takes slightly longer to combine chemically to form hydration products, thus making GGBS concrete a little more sensitive to poor curing. To get the full benefit of GGBS in concrete, it is essential to protect against early loss of moisture during curing. Horizontal surfaces in particular are susceptible to poor curing due to exposure to direct sunlight and strong drying winds.

For GGBS contents of up to 60\%, curing periods as recommended in IS 326 (will be superseded by EC 2) and BS 8110 for Portland cement concretes are sufficient. For higher GGBS contents, these periods may need to be extended. For floor slabs, where high abrasion resistance is required, proper management of the curing regime is essential when GGBS is used in the concrete. A minimum of 7 days curing is required in these instances. Abrasion resistance is more sensitive to curing than to changes in cement or aggregate types.

\section{IPradhan Mantri Awas Yogana Housing For All 2022 Schemes In India}

Housing for all Schemes by Shri Narendra Modiji Honorable Prime Minister of India envisages the vision of Housing for all by the year 2022. The Scheme comes with an aim of constructing more than two crore house across the length $\&$ breadth of nation within a span of next seven years. The target beneficiaries of the scheme would be poor people living under EWS \& LIG categories in urban establishment.

\subsection{Gujarat Housing Board ongoing scheme in various town of Gujarat India}

Gujarat Housing Board came into existence on 1st May 1960 as a result of bifurcation of Bombay State and Bombay Housing Board and inclusion of Saurashtra Housing Board and as per the Gujarat Housing Board Act, 1961. Gujarat slum clearance board merged with effect from 1/04/2007 as slum cell.

\begin{tabular}{|l|l|l|l|l|l|l|l|l|l|l|l|l|}
\hline District \& Category-Wise Ongoing Projects Up to 31/12/2014 \\
\hline \begin{tabular}{l}
$\mid$ \\
\hline
\end{tabular} \\
\hline Year 2012-13
\end{tabular}


Exploring GGBS Utilization in Construction of Residential Projects \& Its Contribution toward..

\begin{tabular}{|c|c|c|c|c|c|c|c|c|c|c|}
\hline 4 & Ahmedabad & Mahesana & Mahesana & 0 & 112 & 291 & 56 & 0 & 0 & 459 \\
\hline 5 & Ahmedabad & Patan & Patan & 0 & 0 & 0 & 0 & 0 & 0 & $\mathbf{0}$ \\
\hline 6 & Vadodara & Akota & Vadodara & 0 & 0 & 144 & 0 & 0 & 0 & 144 \\
\hline 7 & Vadodara & Bharuch & Bharuch & 0 & 0 & 0 & 192 & 0 & 0 & 192 \\
\hline 8 & Surat & Sachin-Kansad & Surat & 0 & 240 & 561 & 228 & 0 & 0 & 1029 \\
\hline 9 & Surat & Bhagdawala & Valsad & 0 & 0 & 833 & 478 & 118 & 118 & 1547 \\
\hline 10 & Rajkot & Sadhana colony & Jamnagar & 0 & 377 & 59 & 0 & 0 & 0 & 436 \\
\hline 11 & Rajkot & $\begin{array}{l}\text { Kailashnagar } \\
\text { colony }\end{array}$ & Bhuj & 0 & 600 & 0 & 0 & 0 & 0 & 600 \\
\hline \multicolumn{4}{|l|}{ Total } & $\mathbf{0}$ & 1809 & 3360 & 2138 & 118 & 118 & 7543 \\
\hline \multicolumn{11}{|c|}{ Year 2013-14 2nd Phase } \\
\hline SR No. & Division & Location & District & EWS & LIG-1 & $\begin{array}{l}\text { LIG- } \\
2\end{array}$ & MIG-1 & MIG-2 & HIG & $\begin{array}{l}\text { Total No. } \\
\text { Of Houses }\end{array}$ \\
\hline 1 & Ahmedabad & Transport Node & Ahmedabad & 0 & 0 & 560 & 392 & 280 & 336 & 1568 \\
\hline 2 & Ahmedabad & Hathijan & Ahmedabad & 448 & 96 & 0 & 0 & 0 & 0 & 544 \\
\hline 3 & Ahmedabad & Chenpur & Ahmedabad & 192 & 280 & 0 & 0 & 0 & 0 & 472 \\
\hline 4 & Ahmedabad & Dahegam & Gandhinagar & 0 & 0 & 0 & 0 & 0 & 0 & $\mathbf{0}$ \\
\hline 5 & Vadodara & Gorwa & Vadodara & 0 & 224 & 332 & 216 & 0 & 0 & 772 \\
\hline 6 & Vadodara & Ankleshwar & Bharuch & 0 & 0 & 0 & 0 & 0 & 0 & $\mathbf{0}$ \\
\hline 7 & Surat & Jahangirabad & Surat & 0 & 0 & 896 & 645 & 162 & 0 & 1703 \\
\hline 8 & Rajkot & Rangolipark & Rajkot & 0 & 0 & 280 & 440 & 444 & 0 & 1164 \\
\hline 9 & Rajkot & $\begin{array}{l}\text { University } \\
\text { Road }\end{array}$ & Rajkot & 0 & 0 & 0 & 108 & 0 & 0 & 108 \\
\hline 10 & Rajkot & Haveliwadi & Junagadh & 0 & 109 & 352 & 0 & 0 & 0 & 461 \\
\hline \multicolumn{4}{|l|}{ Total } & 640 & 709 & 2420 & 1801 & 886 & 336 & 6792 \\
\hline
\end{tabular}

\section{Gujarat Housing Board Ongoing Scheme Work Under Scope Of Cube Construction Engineering Ltd Vadodara Gujarat India}

A short introductory note for Cube Construction Engineering Ltd, Cube Construction Engineering Ltd., (CCEL), CCEL has transformed in a short span of time from a civil contractor to a well groomed infrastructure development and construction company.

Incorporated in the year 2006 as a Public Limited Company, the flagship company CCEL was established in the year 1994, with an aim of accomplishing world-class standards in real estate, property and infrastructure development, and was formerly known as Cube Constructions. The Registered Office is at Vadodara controlling various Projects at various locations. In more than a decade of its working CCEL has emerged as a renowned civil engineering and construction company.

The Company has vision to provide the customers innovative architecture in affordable prices with international quality; Mr. Sanjay C. Shah heads the company as Chairman and Managing Director with other Directors. CCEL has established its capabilities in executing complex and challenging projects in all kinds of environment, having delivered projects in time bound schedules with international standards.

CCEL's expanding list of satisfied clients reflects in its ability to execute challenging projects, despite all odds. The high percentage of repeat orders stand testimony to this. CCEL has achieved many milestones. CCEL's ability to manage operations in diverse industries and economies coupled with its track record in mobilizing financial and human resources has made it the preferred contractor for critical projects.

In Phase II of Gujarat housing Board Scheme CCEL has been awarded 101 towers to build. If CCEL alone is using GGBS as a replacement of Cement it can help to curtail indirect emission of $\mathrm{CO}_{2}$ gas in atmosphere. This is shown in the tabular form below

\begin{tabular}{|c|c|c|c|c|c|c|c|}
\hline \multicolumn{8}{|c|}{ For 1 lacs Tons of Cement to be used in making GHB Projects under CCEL } \\
\hline $\begin{array}{l}\text { Sr. } \\
\text { No }\end{array}$ & $\begin{array}{l}\text { MIX } \\
\text { ID }\end{array}$ & $\begin{array}{l}\text { Probable } \\
\text { Concrete in GHB } \\
\text { in CCEL Scope }\end{array}$ & $\begin{array}{l}\text { Cement } \\
\text { Proportion in } \\
\mathrm{KG} \text { for } 1 \mathrm{CM}^{3}\end{array}$ & $\begin{array}{l}\text { GGBS } \\
\text { Proportion } \\
\text { for } 1 \mathrm{CM}^{3}\end{array}$ & $\begin{array}{l}\mathrm{CO}_{2} \text { Emission } \\
\text { Per Cum of } \\
\text { concrete }\end{array}$ & $\begin{array}{l}\text { Total } \mathrm{CO}_{2} \text { Emission } \\
\text { Per Cum of } \\
\text { concrete in MT }\end{array}$ & $\begin{array}{l}\text { Saving in } \mathrm{CO}_{2} \\
\text { Emission for total } \\
\text { Concrete }\end{array}$ \\
\hline 1 & M30 & 259002 & 400.0 & 0 & 0.37 & 96348.88 & 0 \\
\hline 2 & M25 & 10045 & 365.8 & 0 & 0.34 & 3417.21 & 0 \\
\hline 3 & M20 & 6293 & 350.0 & 0 & 0.33 & 2048.34 & 0 \\
\hline 4 & M30 & 259002 & 200 & 200 & 0.19 & 48174.44 & 51720 \\
\hline 5 & M25 & 10045 & 146.3 & 219.5 & 0.14 & 1366.70 & 2051 \\
\hline 6 & M20 & 6293 & 140 & 210 & 0.13 & 819.34 & 1229 \\
\hline \multicolumn{7}{|c|}{ Overall Saving in Carbon Emission in whole Projects of GHB under CCEL in MT } & 55000 \\
\hline
\end{tabular}




\subsection{Observation}

About one lacs tones cement is used in making of Concrete framed Structure, GGBS as cement replacement is used, and 55000 tons of cement can be saved. The construction Industry through cube only, will help to prevented 52000 tones of $\mathrm{CO}_{2}$ emitted to the atmosphere indirectly. The benefits of use less cement not limited to this, the shrinkage and porosity of concrete are reduces which provides the durability to the concrete structures. India is facing serious air, water, soil, food and noise pollution problems. Every effort therefore is necessary to prevent pollution on top priority basis

There is an appreciable increase in the workability of concrete with increasing percent replacement of cement with GGBS, in addition to this the partial replacement of OPC by GGBS not only provide economy in construction but it also facilitates environmental friendly disposal of the waste slag which is generated in huge quantities from the steel industries.

\section{Conclusions}

The following conclusion is drawn from the study

1) The optimum GGBS replacement as cementation material is characterized by high compressive strength, low heat of hydration, resistance to chemical attack, better workability, good durability and costeffectiveness.

2) The 7-day strength of concrete (at $20^{\circ} \mathrm{C}$ ) with up to $50 \%$ GGBS is slightly lower than concrete with Portland cement only, this is not sufficient to affect formwork striking times or delay construction. Thus the use of 50\% GGBS in concrete mixes provides sufficient strength so as not to have any impact on the contractor's formwork striking programme.

3) Adding GGBS to concrete will result in a small increase in elastic modulus for a given compressive strength, although the differences are not large enough to be of significance in design. Creep of GGBS concrete has been observed to be slightly less than that of concrete made with Portland cement

4) Concrete continues to play a pivotal role in overall economic growth both locally and globally. In order to improve the sustainability of all concrete structures, there is a need to understand the interactive effect of the many issues from 'cradle to grave' in the design phase, during construction and end-of-life and, most importantly, the energy savings achievable during the use phase. This document has summarized what contribution the replacement of Cement by GGBS can contribute in curtailing the main sources of green house gas $\mathrm{CO}_{2}$-emission.

5) The role of concrete prepared with GGBS plays in eliminating the negative impacts of the cement industry, to replace as much Portland cement as possible by supplementary cementitious materials, and using the concrete wisely.

6) Electricity \& heat contributes $40 \%$ of India total Green House Gas Emission. In 200536000 million Metric ton of Carbon dioxide Equivalent was emitted as per World Resources Institute 2099 climate Analysis indicators tool. Construction of 101 Apartment \& 8600 no of Dwelling units by using of GGBS we can save 55000 MT of green house gas emission in atmosphere, if the same is followed for 2 crore dwelling as to be constructed by 2022 under House for all scheme we can contribute @ $0.35 \%$ age cut in overall indirect emission of green house in atmosphere for the whole country. Since most of the big projects in the country are yet to come, energy experts see it also an opportunity to move to cutting-edge technology quickly and adopt a smart concrete.

7) Among the three key moral commitments India has made at Paris (not legally-binding yet) in COP21 Climate Summit, improving the emissions-intensity of its GDP which at present is 2.44 per Capta. The country had committed to reducing its emissions intensity by 33-35 per cent by 2030, compared with 2005 levels. Since it seems to have achieved about 12-15 per cent efficiency improvements in the last decade, India is on target to easily achieve its target. The use of Supplementary material in concrete will help even exceed it.

\section{References}

[1]. Ground granulated blast-furnace slag - Wikipedia, the free encyclopedia

[2]. David O’ Flynn doflynn@ecoum i.e. 0879654891

[3]. http://www.ecocem.ie/technical,working.htm

[4]. http://www.ecocem.ie/technical,strength.htm

[5]. GGBS Brochure JSW Cement

[6]. http://ggbsreviewgroup.blogspot.in

[7]. http://www.vcem-global.com/technical.html

[8]. COP21 Climate Summit.

[9]. Gujarat housing Board Brochure \& Housing for All Schemes

[10]. Kamran Muzaffar Khan, "Effect of blending of Portland cement with Ground Granulated Blast Furnace slag on the properties of concrete" 29th Conference on OUR WORLD IN CONCRETE \& STRUCTURES: 25 - 26 August 2004, Singapore.

[11]. World Resources Institute 2009 Climate Analysis Indicator Tool 
[12]. Vinayak Awasare, Prof. M. V. Nagendra, “ANALYSIS OF STRENGTH CHARACTERISTICS OF GGBS CONCRETE”, IJAET, Vol V (2), June 2014

[13]. S. Arivalagan, "Sustainable Studies on Concrete with GGBS as a Replacement Material in Cement", Jordan Journal of Civil Engineering, Vol 8, (3), 2014

[14]. D. Suresh and K. Nagaraju "Ground Granulated Blast Slag (GGBS) In Concrete - A Review" IOSR Journal of Mechanical and Civil Engineering, Vol 412 Aug. 2015.

[15]. M. Ramalekshmi1, R. Sheeja2, R. Gopinath, "Experimental Behavior of Reinforced Concrete with Partial Replacement of Cement with Ground Granulated Blast furnace Slag, International Journal of Engineering Research \& Technology Vol. 3 (3), March - 2014

[16]. http://www.ukcsma.co.uk/what_is_ggbs.html 